\title{
Development and Fabrication of A Portable Shredding Machine for Rapid Composting of Organic Waste
}

\author{
Resmi G.*† and Vinod V.** \\ *Department of Civil Engineering, N.S.S. College of Engineering, Palakkad, Kerala, India \\ **Department of Mechanical Engineering, N.S.S. College of Engineering, Palakkad, Kerala, India \\ †Corresponding author: Resmi G.; resmivinod@gmail.com
}

Nat. Env. \& Poll. Tech. Website: www.neptjournal.com

Received: 03-06-2021

Revised: 26-06-2021

Accepted: 12-07-2021

Key Words:

Organic waste

Shredder

Accelerated composting

Composting parameters

\begin{abstract}
Solid waste management is found to be a matter of great concern all over the world. As the population grows, the volume of food waste also increases. Vegetable waste discarded from markets, waste discarded from slaughterhouses, and food waste left out after large social gatherings are becoming unmanageable heaps of organic waste. Composting is an effective process that can be used for the biodegradation of solid waste. Researchers have studied the influence of many parameters to accelerate the composting process such as adjusting the $\mathrm{C} / \mathrm{N}$ ratio, $\mathrm{pH}$, temperature, and moisture content. Reducing the size of larger pieces into small particles is found to accelerate the microbial activity and hence composting. This paper discusses the development and fabrication of a shredding machine used for cutting large volumes of vegetable waste. As per the studies conducted, the shredding machine can cut down $360 \mathrm{~kg}$ of vegetable waste into shredded waste within one hour. The quantity of petrol required for operating the engine for one hour was observed as one liter. Hence the fabricated shredding machine is found as cost-effective. The portable unit can be taken to various locations where solid organic waste has to be shredded and hence there is no need to transport waste which is a cumbersome task that consumes more energy.
\end{abstract}

\section{INTRODUCTION}

As the world populations grow there occurs increased demand for food as well as various consumable items. The rate of production of waste also gets increased as a result of this. Almost all parts of the world are struggling to manage the huge heaps of garbage dumps generated by this. It is stated by National Environmental Engineering Research Institute (NEERI) that the per capita generation of municipal solid waste in large cities of India is around $0.5 \mathrm{~kg}$ per day. Many vegetable markets, slaughterhouses, etc. generate large quantities of organic waste. In many places, unscientific and crude methods are used for the disposal of this waste. If proper treatment is not provided, these wastes start emitting a bad odor. Among the various solid waste management techniques used, such as landfilling, incineration, pyrolysis, etc. composting is found to be the best-suited method for managing biodegradable solid waste (Argun et al. 2017). It is an environmentally safe method as the mature compost can be used as a bio-fertilizer.

Aerobic composting leads to mature compost when all factors affecting composting are properly monitored (Jain et al. 2019). But one of the major problems is the requirement of the long time needed for the formation of compost. Many researchers have studied various parameters of composting and they have found that $\mathrm{pH}$, temperature, $\mathrm{C} / \mathrm{N}$ ratio of waste, and moisture content are some of the most important factors influencing the nature of compost. (Ameen et al. 2016, Sundberg \& Jonsson 2016, Nikaju et al. 2018). It is reported that the addition of inoculum with microbial culture will accelerate the composting activities (Pan et al. 2012, Payel \& Rounak 2017). Some of the researchers have also observed that reduction of the size of waste has a good influence on microbial decomposition (Tanugur 2009, Jain et al. 2019). Cutting or chopping of organic waste is therefore highly needed for compost acceleration (Pavankumar et al. 2018). As manual cutting is a time-consuming process it was decided to develop a shredding machine that satisfies our requirements. Some researchers have studied the performance of agricultural waste shredder machines for reducing the size of organic waste such as coconut leaves (Sanjay Kumar \& Hemanth Kumar 2015). The existing system of machines used for composting depend on manual labor for its operation and it is a time-consuming process (Katiar et al. 2019). As an improvement over this, a machine connected with an engine and a gearbox was designed. Many researchers have emphasized the importance of shredding matter for active decomposition but the cost to buy a shredder is not afforda- 
ble for the tail end users. Hence a shredding machine that can be manufactured in a cost-effective manner is designed. The machine is working with petrol and the wheel assembly provided helps the users to take to various destinations such as market areas or dumbing yards where waste accumulation is taking place. In every integrated municipal solid waste management (MSWM) facility, composting is given special importance as it is well suited for the decomposition of organic waste. In the case of the success story of Indore Municipal Corporation (IMC), India small composting units were deployed in integrated MSWM (Prashant et al. 2021).

\section{MATERIALS AND METHODS}

The research work mainly concentrated on the development of various parts and the fabrication of a shredding machine suitable for cutting down huge organic waste. Also, composting studies are done using two methods 1 . Raw vegetables cut manually and 2. Vegetables shredded with the shredding machine. In each case, the vegetables were collected from the local market and aerobic composting was carried out under laboratory conditions. Analysis of variation in temperature, $\mathrm{pH}$, and moisture content in the composting samples was carried out to observe the time needed for mature compost formation.

\section{Shredding Machine}

The shredding machine comprises of main parts like 1.5 HP petrol engine, gearbox, two sets of shredder blades (primary and secondary), hopper for putting the biowaste, a tray for collecting the shredded organic matter (Table 1).

The following figures show the graphical representation of the machine. 3D view of the machine (Fig. 1) gives an idea about the overall shape of the machine.

Fig. 2 shows the position of the engine connected to the gearbox through a chain pulley. The gearbox is connected to the primary and secondary blades through a chain drive. The hopper for feeding the vegetable waste to the primary

Table 1: Specifications of the machine.

\begin{tabular}{|c|c|c|}
\hline $\begin{array}{l}\text { S1 } \\
\text { No. }\end{array}$ & Item Name & Specifications \\
\hline 1 & Engine & $\begin{array}{l}\text { Fuel Type- Petrol, } 4 \text { Stroke, 3.5BH- } \\
\text { P@3600Rpm }\end{array}$ \\
\hline 2 & Gear Box & Ratio 1:40, Load Capacity-2 Ton \\
\hline 3 & $\begin{array}{l}\text { Shredding } \\
\text { Blades-Primary }\end{array}$ & Dimensions $472 \mathrm{~mm}$ x262mm \\
\hline 4 & $\begin{array}{l}\text { Shredding } \\
\text { Blades-Secondary }\end{array}$ & Dimensions $360 \mathrm{~mm} \times 262 \mathrm{~mm}$ \\
\hline
\end{tabular}

blades and the collection of shredded waste in the discharge tray is also shown in the side view.

The top view of the machine is given in Fig. 3. The primary shredder blades which are visible through the hopper are shown in the figure.

Based on the developed design and $3 \mathrm{D}$ views the machine was fabricated and the pictures of the shredding machine are shown in the following figures (Figs. 4, 5).

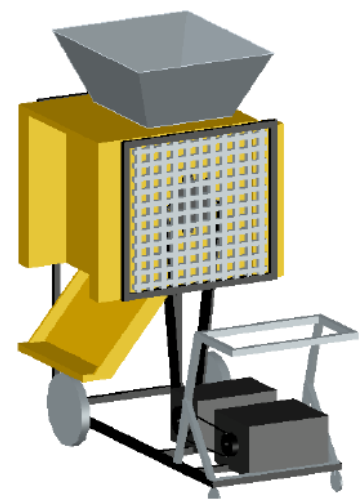

Fig. 1: 3D view of the machine (Graphical representation).
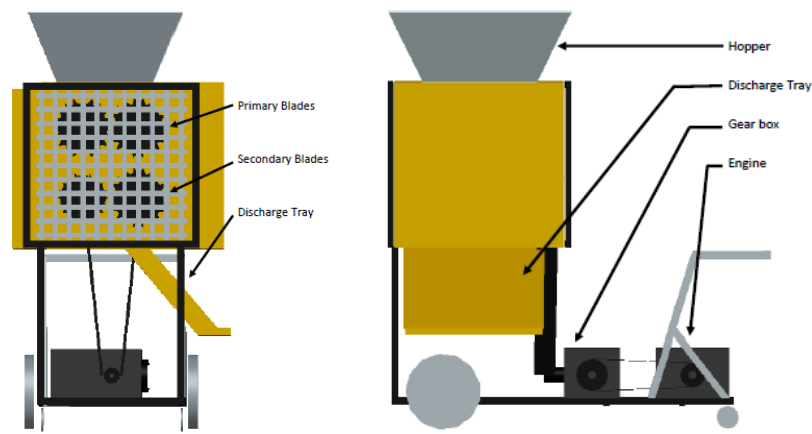

Fig. 2: Side views of the machine (Graphical representation).

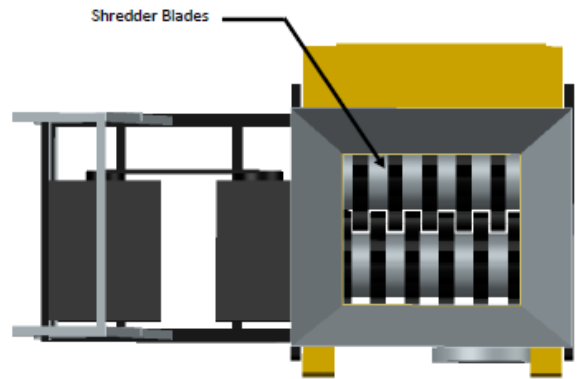

Fig. 3: Top view of the machine (Graphical representation). 
A 4 stroke petrol engine with 3.5 BHP is used to power the machine with a gearbox having a gear ratio of 1:40. It provides ample torque for taking the load for shredding the matter. The shredding blades are made of steel with specialized contours to shred the organic waste into reduced size. The machine has two sets of shredding blades. One primary blade set consists of two specially set steel contour rollers with spacers in such a way that the materials which are placed in the hopper will be directed to it. The primary rollers are aligned with more center to center spacing compared to the set of secondary rollers. The vegetable waste to be shredded is kept in the hopper and when passed through the primary hopper it will be shredded into pieces. It will be again fed into the secondary rollers to shred into still smaller particles.

The secondary sets of rollers with special contours have very little spacing so that the waste particles after passing through these rollers will be crushed to the reduced form. The powdered vegetable waste will be coming out through the discharge tray kept at the bottom. The side panels of the machine are made using SS steel sheets to avoid corrosion. The gear wheels for the primary and secondary blades are protected using the metallic mesh so that effective heat transfer is made during its working. Maintenance operations can be effectively done with this arrangement.

The entire machine is fixed in four castor wheels so that it can be transported from one place to another very easily. The entire size of the machine is $2 \mathrm{~m}$ (Length) $\times 1 \mathrm{~m}$ (Width) $\times$ $1.6 \mathrm{~m}$ (Height). Thus it is very compact and portable.

\section{Bio Bin Formation}

Aerobic composting was carried out in specially designed buckets. The bins had holes all around so that aerobic conditions could be maintained inside (Fig. 6). Daily mixing and turning of waste were done to ensure aeration. Layers in the bins were formed with vegetables, printed paper, dry leaves, and coir pith added with microbial inoculum. The

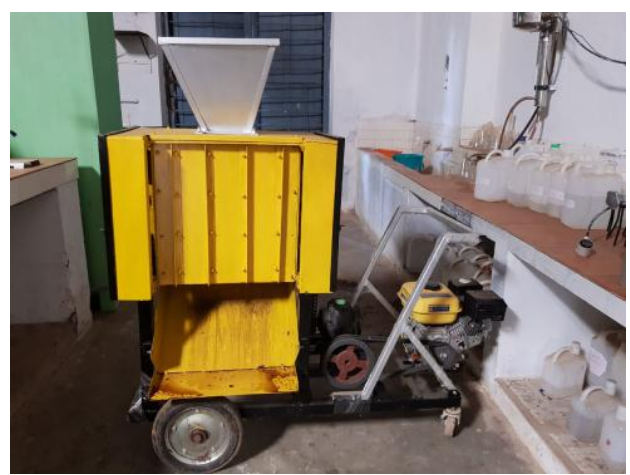

Fig. 4: Side view of the shredding machine. proportion was so adjusted that the resulting $\mathrm{C} / \mathrm{N}$ ratio was less than 30:1. The $\mathrm{C} / \mathrm{N}$ ratio values of all ingredients were calculated separately and the ratio of the sample was obtained as 26:1. Comparison of accelerated composting was made between vegetables cut manually (Fig. 7) and that shredded using the machine (Fig. 8) based on the parameters like $\mathrm{pH}$, temperature, and moisture content.

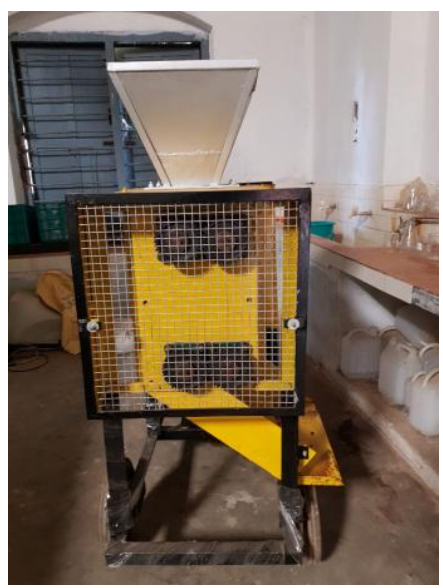

Fig. 5: Rear view of the shredding machine.

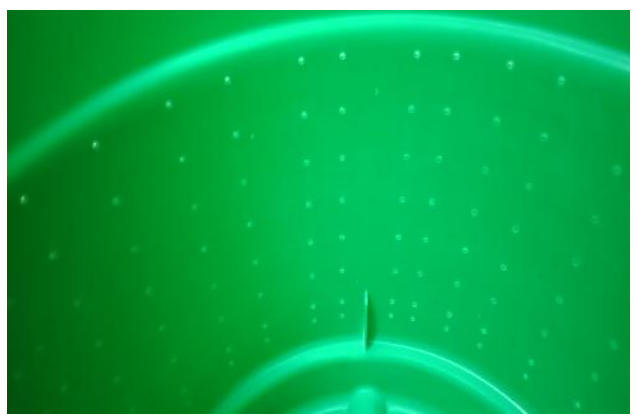

Fig. 6: Bins with openings all around.

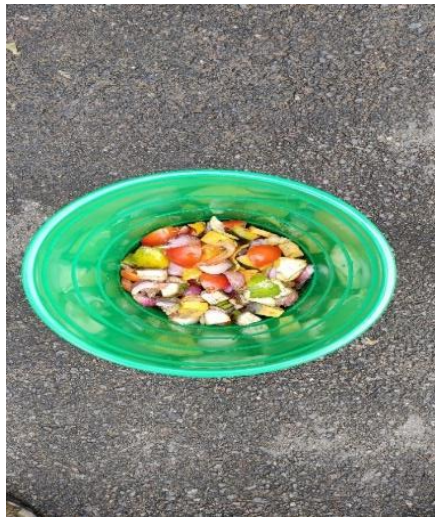

Fig. 7: Vegetables cut manually. 


\section{Composting}

Raw vegetables collected from the market were used for the study. Mainly Potato, cucumber, onion, Tomato, Orange, and Banana were taken for the initial trials. First of all, the vegetables were cut into small pieces manually. Then the layers of cut vegetables were sprayed with inoculum based on coir pith. Specially designed bins with holes all around and with meshed lids were used for aerobic composting. The physical characteristics, $\mathrm{pH}$, temperature, and moisture content were monitored at regular intervals. Two sets of treatments were done. One was with manually cut vegetables of size $10-30 \mathrm{~mm}$ (Sample 1). In the second treatment, the sets of experiments were repeated with shredded vegetables (Sample 2). The comparison of the influencing parameters till 90 days or up to the compost maturity was done.

\section{Testing of Parameters}

Physical parameters influencing the composting were monitored continuously in the bio bin. The temperature of the compost was observed daily using a digital thermometer. The temperature in the top, middle and bottom portions of the bio bin were observed and an average value was taken for reporting. For measuring $\mathrm{pH}$, the method described by Anncarol et al. (2019) was used. For this $10 \mathrm{gm}$ of compost was taken from the compost bin and put into a $250 \mathrm{~mL}$ beaker having $90 \mathrm{~mL}$ distilled water in it. The mixture was stirred well and allowed to settle. the $\mathrm{pH}$ of the supernatant was tested using a digital $\mathrm{pH}$ meter.

\section{RESULTS AND DISCUSSION}

\section{Performance Evaluation of Shredding Machine}

During initial testing, the time taken for shredding $15 \mathrm{kgs}$ of vegetable waste was around 2.5 minutes. The vegetables were passed through the hopper twice to pass through the primary and secondary blades for better shredding into smaller particles. Even though cutting down of organic matter helped accelerate the composting; the formation of fine powder is not advisable. While particle size reduction is favorable for biological activities, minimizing the size to fine powder form leads to slumping and compaction of the material (Zhang et al. 2019). The presence of slightly larger particles ensures bigger void spaces and better oxygen access. The shredding was repeated twice for making the waste into a mass with crushed form as well as medium-sized pieces. It is observed that if the machine is effectively loaded the machine is capable of converting around $360 \mathrm{~kg}$ of vegetable waste into a fine mix in one hour. The fuel consumption for the operation of the machine was measured at around 1 liter for one hour. Thus at the expense of one liter of petrol, vegetable waste of any type around $360 \mathrm{kgs}$ can be converted into small particles so that it can be effectively converted into bio compost.

The main advantage of the machine fabricated is that it is light in weight, portable, and very compact. Since this machine is running on petrol fitted with the gearbox to take uploads and portable it can be used for continuous running applications like composting units. This can also be a livelihood for different neighborhood groups such as Kudumbashree units (Kudumbashree Mission is the Kerala State Government's instrument for poverty eradication under the Local Self-Government Department) to earn money for making compost and converting it into manure.

\section{Studies on Compost Maturity}

Compost maturity and stabilization were monitored through parameters such as $\mathrm{pH}$, Moisture level, and physical characteristics of compost. The vegetables which were shredded manually and with the help of a shredding machine were
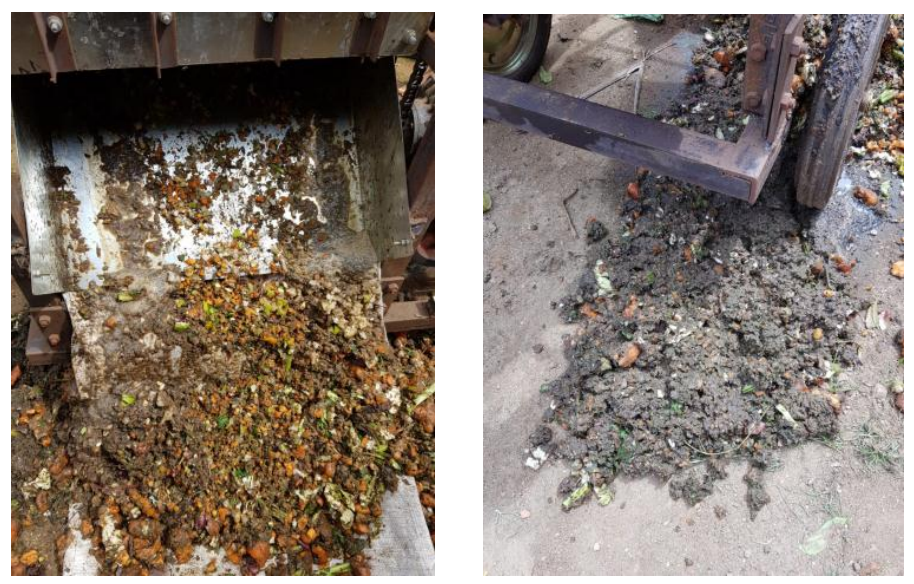

Fig. 8: Vegetable waste shredded using the machine (Left- first trial, Right- Second trial) 
taken and filled in separate bins. The productivity of the shredding machine is very high compared to manual shredding. It was observed that the quantity of vegetable waste that can be processed by the machine is around 20 times more compared to manual cutting by a single individual and it also takes only nearly one-tenth of the time for its processing the entire mass into smaller particles.

Physical characteristics of the compost were noted and the bin having maximum bacterial activity and shorter compost duration was noted down. The physical nature of compost like color, temperature, smell, and moisture content was observed directly. The physical changes in compost were observed every day.

Observation on the 5 th day showed no remarkable change in color or heat formation in the bin carrying the vegetables cut manually (Sample 1). There was little variation in some of the physical characteristics in the compost bin containing the shredded waste (Sample 2). A slight foul smell combined with medium moisture content was noted by the $10^{\text {th }}$ day in Sample 1. The $\mathrm{pH}$ variation, heat change, and change in moisture content were monitored continuously. The readings are represented in the following graphs. For sample 1 there were remarkable changes observed from the second week onwards. But sample 2 took three weeks to start with changes in physical characteristics.

\section{Variation in Temperature}

Temperature indicates the microbial activity taking place in the bin during the composting process. It is one of the key factors influencing the degradation process (Jain et al. 2019). A few days after starting, the temperature in the compost samples showed an increasing tendency. This increase was steady in sample 1 and it was rapid in sample 2. The rapid increase of temperature in sample 2 to the thermophilic range may be due to the higher microbial activity on the substrate.

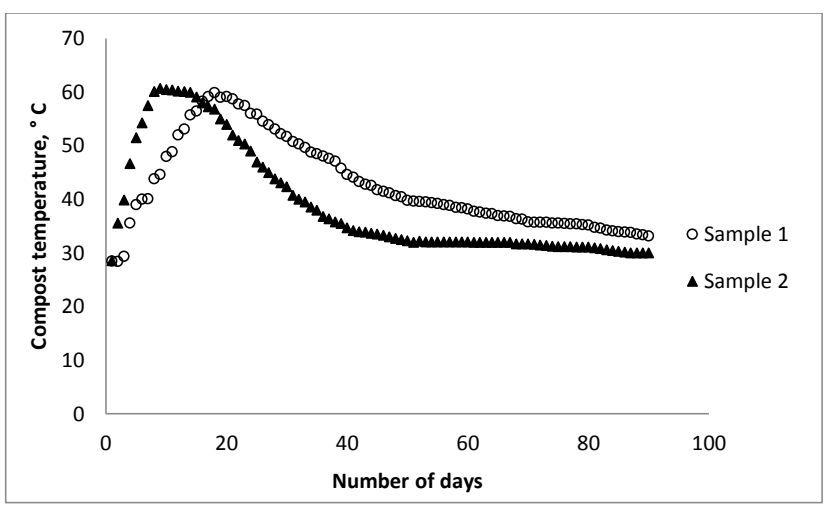

Fig. 9: Variation in temperature during composting.
The following graph (Fig. 9) shows the changes observed in both cases.

As per the study, it could be observed that the bio bin containing vegetables cut in the shredding machine and bulking agents with inoculum i.e. sample 2 have reached the thermophilic stage very rapidly. The maximum temperature was observed on the $9^{\text {th }}$ day and it was around $60.7^{\circ} \mathrm{C}$. In the case of sample 1 maximum temperature was observed on the $18^{\text {th }}$ day and it was $59.9^{\circ} \mathrm{C}$. In the case of sample 2 , composting continued in thermophilic and mesophilic stages for one month, and then it started showing stability. After 45 days stable temperature was observed for sample 2. While in the case of manual shredding of vegetables this phenomenon was not observed. The thermophilic and mesophilic stages lasted for 50 days duration. It is reported that temperature between 30 and $55^{\circ} \mathrm{C}$ enhance microbial activity (De Bertoldi et al. 1983) Nearly stable condition was noticed from 80 days onwards. During the observation continued for 90 days, the temperature in the compost bin did not reach ambient temperature. It could be understood that the shredding of waste to small pieces using the shredding machine is highly effective in accelerating the composting process. Fig. 10 shows the compost obtained using shredded waste after two weeks.

\section{Variation in Moisture Content}

Moisture content in the compost bin is a factor that significantly influences the process of composting. If vegetables alone are taken it may lead to large moisture content and it may lead to the development of anaerobic conditions. Hence dry leaves and paper were added to the samples. Also, the coir pith-based inoculum was highly effective in absorbing moisture and maintaining aerobic conditions in the bin. Even though moisture was developed during the decomposition it was getting absorbed by the other accelerators and bulking agents added. Initial moisture content in the vegetables was as high as $84 \%$. Due to the mixing with bulking agents, the initial moisture content in the compost bin was observed as $68 \%$. Reduced moisture content shows increased microbial

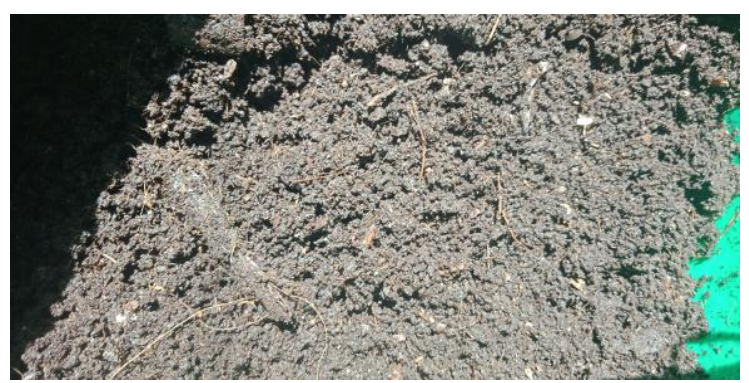

Fig. 10: Compost formation after $18^{\text {th }}$ day. 
activity (Ameen et al. 2016). This may be due to the presence of the anaerobic condition in sample 1 where more moisture is present in the waste. The waste contained in the bin by manual cutting of vegetables showed a reduction in moisture content on a gradual basis (Sample 1). There was a rapid reduction of moisture content in the shredded waste sample (Sample 2). The figure below shows the reduction occurred in moisture content during composting process (Fig. 11). It shows that the shredding of waste is accelerating the absorption of moisture and leachate generated in the bin.

This is due to the reason that as the waste is shredded into smaller particles its surface area is increased and this improves the amount of heat transfer and thus the moisture is removed at a faster pace compared to manual shedding. It can be observed from the graph that within 10 days the sample 2 shows a reduction in moisture content of $10 \%$ and sample 1 takes nearly 30 days to reach the same moisture content. Thus a significant improvement in moisture reduction is observed due to shredding.

\section{Variation in pH}

Continuous monitoring of $\mathrm{pH}$ was carried out using a digital $\mathrm{pH}$ meter. The variation in $\mathrm{pH}$ indicated the progress of biological activities going on inside the bio bin during the composting process. In the present study, there was an increase in $\mathrm{pH}$ during the initial phase of composting. Compared to sample 1 the variation was rapidly occurring in sample 2 (Fig. 12). This may be due to the higher activity of microorganisms when the particles are very small in size. It is reported by many investigators that bacterial culture will take part in decomposition and as a result ammonium will be formed. At a later stage, there is a chance for reduced $\mathrm{pH}$ when Carbon dioxide and organic acid production starts (Zakarya et al. 2018). In the current experimental investigation $\mathrm{pH}$ in the compost bin was always in a range of 6.8 to 7.9. In the case of maximum and minimum $\mathrm{pH}$, there was no significant variation between manually cut organic matter and those shredded using the machine. But $\mathrm{pH}$ increased to 7.9 by the end of 5 days in shredded waste. It shows that

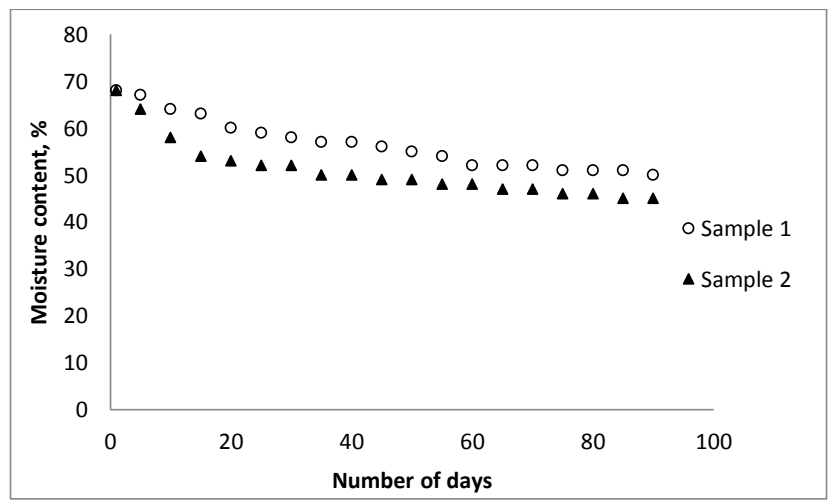

Fig. 11: Variation in moisture content during the composting process.

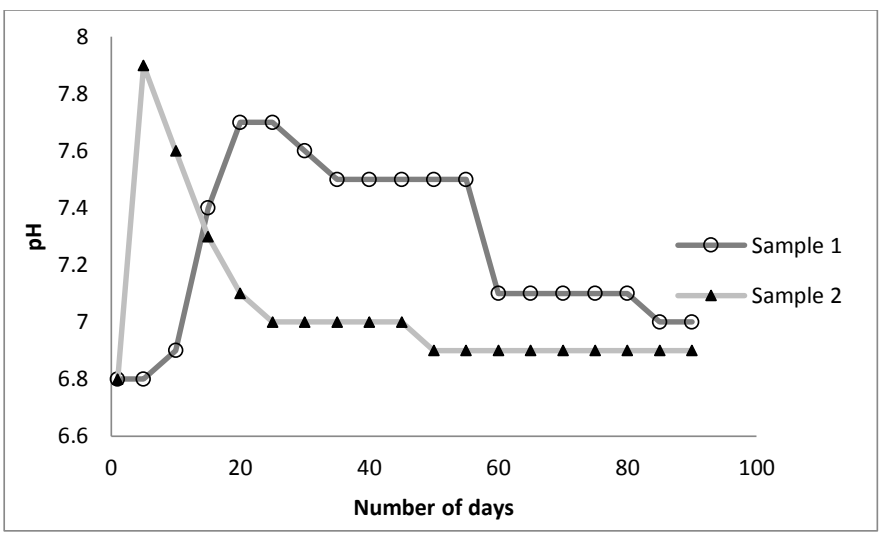

Fig. 12: Variation in $\mathrm{pH}$ during the composting process. 
organic matter powdered using the machine is acted upon by the micro-organisms without delay. The gradual change in $\mathrm{pH}$ was observed in sample 1 . The value of $\mathrm{pH}$ reached to neutral condition by 25 days in sample 2 and it took nearly 85 days in the case of sample 1 . Studies in composting have shown that starting with a fairly neutral $\mathrm{pH}$ will ensure high levels of microorganisms for efficient decomposition and the $\mathrm{pH}$ should be around neutral conditions for obtaining stable compost (Risse \& Faucette 2009).

\section{CONCLUSION}

A portable shredding machine was fabricated for cutting down organic waste and composting carried out. The benefit of shredding is that as the waste particles are properly shredded, the surface area of the waste materials will be increased so that they can be effectively degraded by microorganisms. As a result, the efficiency of composting is increased and productivity is improved. Neutral $\mathrm{pH}$ condition was reached within 25days for shredded waste. Thermophilic conditions occurred rapidly and mesophilic decomposition started after two weeks duration. After one month of decomposition, moisture content was within the range of $50 \%$ to $40 \%$ which was ideal for good compost. Composting done by vegetables cut manually has taken nearly 80 days to reach stable conditions. Thus with the help of shredding machines within lesser time, more waste can be converted into manure. This portable unit can be utilized in restaurants, auditoriums, housing colonies, markets, etc. The panchayats can even use this portable machine as a mobile unit with the help of Kudumbashree units to operate in various housing colonies at least once a week to convert the collected waste from houses and turn it into powder. Hence the need for the collection and transportation of vegetable waste can be avoided. Composting plays a vital role in environmental regulations because the discarded organic waste can be converted into value-added product/ manure at the source itself. As landfill space is reducing day by day and the fee for transport of waste is getting increased there is wider scope for accelerated composting. It can be concluded that with the help of a shredding machine effective waste management can be achieved in a highly economical and sustainable manner.

\section{ACKNOWLEDGMENT}

The authors gratefully acknowledge the financial assistance provided by APJ Abdul Kalam Technological University, Centre for Engineering Research and Development (CERD) as Research Seed Money (RSM) for carrying out the experimental investigations at N.S.S. College of Engineering Palakkad, Kerala, India.

\section{REFERENCES}

Ameen, A., Ahmad, A., Munir, N. and Raza, S. 2016. Physical and chemical analysis of compost to check its maturity and stability. Eur. J. Pharm. Med. Res., 3(5): 84-87.

Anncarol, W.K., Ezekiel, M.N. and Maingi J.M. 2019. Assessment of physic-chemical changes during composting rice straw with chicken and donkey manure. Int. J. Recycl. Org. Waste Agric., 8 (1): S65-S72.

Argun, Y., Karacali, A., Calisir, U. and Kilinc, N. 2017. Composting is a waste management method. J. Int. Environ. Appl. Sci., 12(3): 244-255

Jain, M.S., Daga, M. and Kalamdhad, A.S. 2019. Variation in the key indicators during composting of municipal solid organic wastes. Sustain. Environ. Res., 29(9): doi.org/10.1186/s42834-019-0012-9.

Katiar, A., Gaur A., Shrivastava, A., Khan, M.A., Sing, N.P., Saini, R. and Kaur, G. 2019. Design and construction of a shredding machine for recycling and management of organic waste. Int. J. Sci. Res. Dev., 3(4): 707-712.

De Bertoldi, G., Vallini, M. and Pera, A. 1983. The biology of composting: A review. Waste Manage. Res.. 1(2): 157-176.

Nikaju, J., Borkar, V., Pise, A. and Pawar, S. S. 2018. Organic waste compost machine, International Conference on Emanations in Modern Engineering Science \& Management (ICEMESM-2018), 23-24 March 2018, Nagpur Maharashtra, India, IJET, India, pp. 1-5

Pan, I., Dam, B. and Sen, S.K. 2012. Composting of common organic wastes using microbial inoculants. Biotech, 2: 127-134 https://doi. org/10.1007/s13205-011-0033-5.

Pavankumar, S.B., Sachin, K.R., Shankar, R., Thyagaraja, B. and Madhusudhan, T. 2018. Design and fabrication of organic waste shredding machine. Int. J. Engg. Sci. Invent., 7(6): 26-31.

Payel, S. and Rounak, C. 2017. Bioconversion of organic solid wastes into biofortified compost using a microbial consortium. Int. J. Recycl. Org. Waste Agricult., 6: 321-334.

Prashant, S., Sharma, P.K., Pandey, S. and Chintala V. 2021. Unsegregated municipal solid waste in India: Current scenario, challenges, and ways forward. Nature Environ. Pollut. Technol., 20(2): 851-863.

Risse, M. and Faucette, B. 2009. Food waste composting: Institutional and Industrial Applications What Is Compost? Univ. Georg., 1189: 1-8.

Sanjay Kumar, I.M. and Hemanth Kumar, T. R. 2015. Design and development of agricultural waste shredder machine. Int. J. Innov. Sci. Engg. Technol., 2(10): 164-172.

Sundberg, C. and Jonsson, H. 2016. Higher pH and faster decomposition in bio-waste composting by increased aeration. Waste Manage., 28(3): 518-526.

Tanugur, I. 2009. Aerobic composting of broiler waste with different amendments. M.Sc. thesis. Institute of Science and Technology, Istanbul Technical University, Istanbul Turkey.

Zakarya, I.A., Khalib, S.N.B. and Ramzi, N.M. 2018. Effect of pH, temperature, and moisture content during composting of rice straw burning at different temperatures with food waste and effective microorganisms. E3S Web of Conf., 34: 02019. https://doi.org/10.1051/ e3sconf/20183402019

Zhang, Y., Kusch-Brandt, S., Gu, S. and Heaven, S. 2019. Particle size distribution in municipal solid waste pre-treated for bioprocessing. Resources, 8(166): 1-24. doi:10.3390/resources8040166 